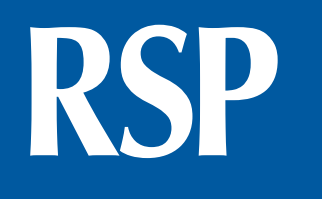

http://www.fsp.usp.br/rsp/

Revista de Saúde Pública

\title{
Caesarean birth rates in public and privately funded hospitals: a cross-sectional study
}

Bruna Dias Alonso', Flora Maria Barbosa da Silva", Maria do Rosário Dias de Oliveira Latorre ${ }^{\text {III }}$ Carmen Simone Grilo Diniz ${ }^{\mathrm{IV}}$, Debra Bick ${ }^{\mathrm{V}}$

I Universidade de São Paulo. Faculdade de Saúde Pública. Programa de Pós-Graduação em Saúde Pública. São Paulo, SP, Brasil

" Universidade de São Paulo. Faculdade de Saúde Pública. Escola de Artes, Ciências e Humanidades. Departamento de Saúde Materno-Infantil. Graduação em Obstetrícia. São Paulo, SP, Brasil

III Universidade de São Paulo. Faculdade de Saúde Pública. Departamento de Epidemiologia. São Paulo, SP, Brasil

Iv Universidade de São Paulo. Faculdade de Saúde Pública. Departamento de Saúde Materno-Infantil. São Paulo, SP, Brasil

$\checkmark$ King's College London. Florence Nightingale Faculty of Nursing and Midwifery. London, United Kingdom

\section{ABSTRACT}

OBJECTIVE: To examine maternal and obstetric factors influencing births by cesarean section according to health care funding.

METHODS: A cross-sectional study with data from Southeastern Brazil. Caesarean section births from February 2011 to July 2012 were included. Data were obtained from interviews with women whose care was publicly or privately funded, and from their obstetric and neonatal records. Univariate and multivariate analyses were conducted to generate crude and adjusted odds ratios (OR) with $95 \%$ confidence intervals $(95 \% \mathrm{CI})$ for caesarean section births.

RESULTS: The overall caesarean section rate was $53 \%$ among 9,828 women for whom data were available, with the highest rates among women whose maternity care was privately funded. Reasons for performing a c-section were infrequently documented in women's maternity records. The variables that increased the likelihood of c-section regardless of health care funding were the following: paid employment, previous c-section, primiparity, antenatal and labor complications. Older maternal age, university education, and higher socioeconomic status were only associated with c-section in the public system.

Bruna Dias Alonso

Rua Oscar Freire, 2371 Apto 83 Pinheiros

05409-012 São Paulo, SP, Brasil

E-mail: bruna.dias.alonso@gmail.com

Received: Mar 28, 2016

Approved: Oct 18, 2016

How to cite: Alonso BD, Silva FMB, Latorre MRDO, Diniz CSG, Bick D. Caesarean birth rates in public and privately funded hospitals: a cross-sectional study. Rev Saude Publica. 2017;51:101.

Copyright: This is an open-access article distributed under the terms of the Creative Commons Attribution License, which permits unrestricted use, distribution, and reproduction in any medium, provided that the original author and source are credited.

CONCLUSIONS: Higher maternal socioeconomic status was associated with greater likelihood of a caesarean section birth in publicly funded settings, but not in the private sector, where funding source alone determined the mode of birth rather than maternal or obstetric characteristics. Maternal socioeconomic status and private healthcare funding continue to drive high rates of caesarean section births in Brazil, with women who have a higher socioeconomic status more likely to have a caesarean section birth in all birth settings.

DESCRIPTORS: Cesarean Section, statistics \& numerical data. Health care Financing. Maternal-Child Health Services. Socioeconomic Factors. Cross-Sectional Studies. 


\section{INTRODUCTION}

High rates of caesarean section (CS) are a public health issue. Overall CS rates higher than $10 \%$ to $15 \%$ are not associated with improved maternal or infant outcomes ${ }^{1}$. However, CS rates are increasing globally ${ }^{2}$. This rise has been particularly significant in Brazil, where the overall CS rate increased from $33 \%$ in $1991^{3}$ to $51.9 \%$ in $2012^{4}$. The high number of CS births in the privately funded healthcare sector makes a significant contribution to the high overall rates in Brazil, with CS rate as high as $80 \%$ in these settings ${ }^{3,5}$, independent of maternal or fetal complications during pregnancy or labour 5 .

The lack of routinely collected data in Brazil on CS clinical indications does not enable planned or emergency CS procedures to be considered separately. Maternal characteristics such as age, being overweight or obese at pregnancy commencement, and ethnicity ${ }^{6,7}$ do not explain variations in CS rates within or between countries. However, differences in criteria for fetal distress and dystocia ${ }^{8}$, organization of health care services ${ }^{9}$, and funding of maternity care ${ }^{10}$ have all been shown to influence CS rates. Therefore, an investigation of potential associations between maternal and obstetric variables and CS outcomes should also include how care was funded ${ }^{10}$. In Brazil, women access maternity care either through the unified national health system, the Sistema Único de Saúde (SUS), or through private healthcare providers. In 2012, nearly $25 \%$ of all births in Brazil were privately funded ${ }^{5}$. The payment to the clinician for assisting either a CS or a vaginal birth does not differ within the private and publicly funded systems, but a scheduled CS is time-saving and enables doctors to better organize their workload in private services ${ }^{11}$.

This study aimed to examine maternal and obstetric factors associated with CS births among women by primary source of health care funding (public or private).

\section{METHODS}

A cross-sectional study was undertaken using data from the "Birth in Brazil" survey (Nascer no Brasil), conducted from February 2011 to July 2012 inclusively. This was the largest study to date to examine the impact of contemporary labor and birth management in Brazilian maternity settings on women's health outcomes. Details on data collection and sampling methods have been described previously ${ }^{12,13}$.

Survey inclusion criteria included women with live infants (regardless of weight and gestational age) and women who had stillborn infants (weighing $\geq 500$ g or gestational age $\geq 22$ weeks) who gave birth in hospitals with 500 births or more in 2007. Women were excluded if they had a home birth, were unable to speak or read Portuguese, had a hearing impairment, severe mental illness, a termination of pregnancy, multiple pregnancies, or an instrumental birth (Figure).

Six strata were created to calculate the sample size for each of the five macro-regions of the country: a capital or regional city hospital, and public, private or mixed funded hospitals (listed in the National Health Establishment Information System as private but with some beds contracted by SUS). In each stratum, random sampling was conducted in two stages: hospital and postnatal women. The sample size of each stratum was calculated based on CS prevalence in Brazil in $2007(46.6 \%)^{12}$. A stratified random sample with proportional allocation took into account the numbers in each type of hospital selected. A 1.3 adjustment factor was used to calculate the size of cluster sampling, with each stratum estimated to provide between 444 to 450 women.

Ninety women were recruited from each hospital. In hospitals with fewer than 12 births a day, all women eligible were invited to participate. In hospitals with more than 12 births a day, women were selected using a sampling frame to ensure it included women who had given birth over the 24-hour period and on all days of the week.

Data collection included interviews with women prior to hospital postnatal discharge and routine data from obstetric and neonatal records. Information from women's interviews 
- Hospitals with $\geq 500$ deliveries in 2007

- Postnatal women with live newborns

- Postnatal women with a stillbirth with $\geq 500 \mathrm{~g}$ and/or gestational age $\geq 22$ weeks

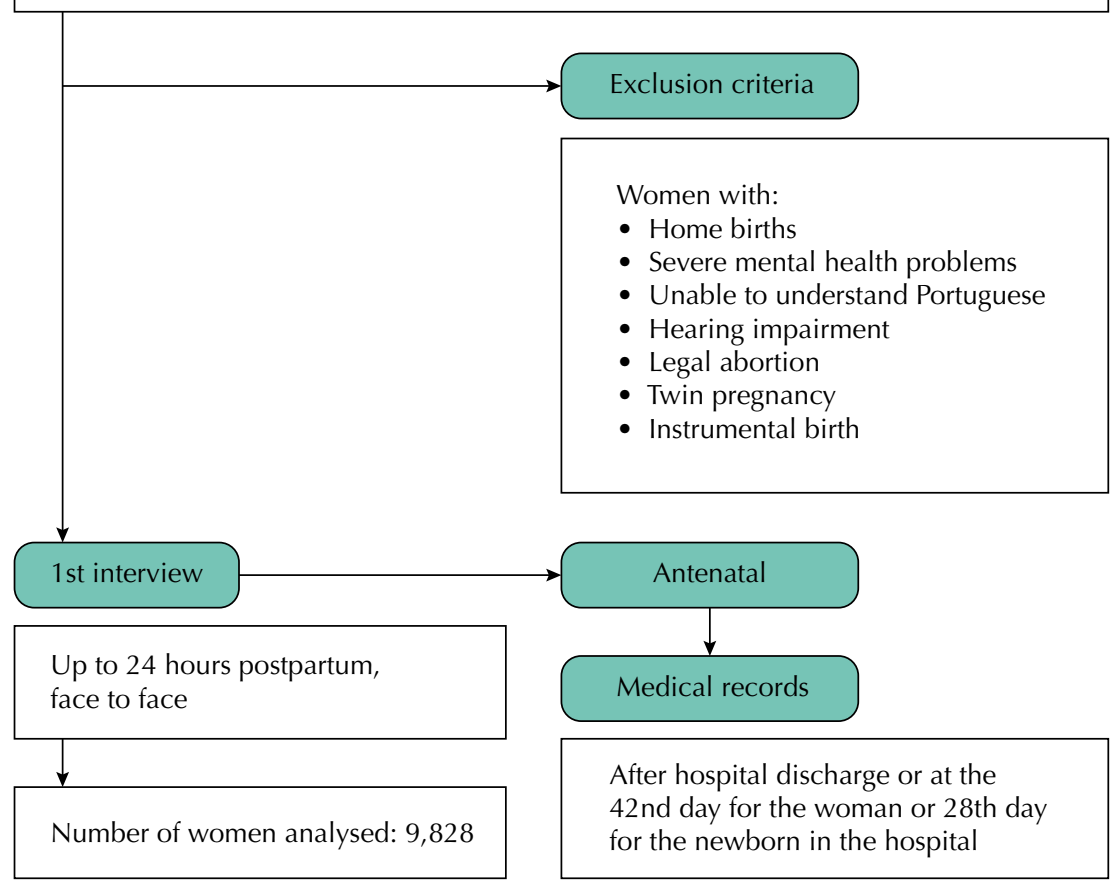

Figure. Data collection flowchart.

was matched with their obstetric and neonatal records and antenatal charts (presented by $96.3 \%$ of women at the hospital admission) ${ }^{14}$ to supplement data that were frequently missing from these records. Women were followed up on day 28 (about their infant's health) and day 42 (about their own health), including women transferred to other hospitals during labor or immediate postnatal period.

Only data from the Southeast region of Brazil are presented in this paper, which includes the states of São Paulo, Rio de Janeiro, Minas Gerais, and Espírito Santo and accounts for around $40 \%$ of the Brazilian population and the largest number of people with access to private healthcare. The region generates the largest gross income in Brazil. The main outcome variable in the study presented here was the mode of birth, classified as vaginal birth or CS. Analyses were conducted for these two groups, which were further classified into whether maternity care was privately or publicly funded.

We investigated maternal socioeconomic and demographic characteristics including age, skin colour (which is how ethnicity is recorded in Brazil), years in full-time education, marital status, employment status, economic status, location of the hospital, obstetric characteristics (previous CS and complications during index pregnancy or labour), and association with CS birth.

The rate of complications were estimated using composite variables based on maternal risk status and included one or more of the following, based on data from women's interviews, antenatal charts, and maternal records: antenatal complications (including diabetes, chronic hypertension, cardiac disease, severe anaemia or other haemoglobinopathies, asthma, lupus or scleroderma, hyperthyroidism, chronic kidney disease, seizures or epilepsy, stroke, chronic liver disease, psychiatric disease, placenta praevia, abruption placenta, gestational hypertension, gestational diabetes, urinary infection, syphilis, HIV, and admission during pregnancy); and labor complications (including stroke, dystocia, dyskinesia, placenta 
praevia, meconium, fetal distress, preterm or post term gestation, restricted fetal growth, polyhydramnios or oligohydramnios, vaginal haemorrhage, and breech presentation).

Univariate and multivariate analysis were undertaken. Analyses were weighted to take account of the effect of the study design. For multivariate analysis, all variables were included in a binary logistic regression model using a stepwise forward process to enable comparisons between outcomes of interest and funding of care. In the final model, variables with ap $<0.05$ were identified

Table 1. Socioeconomic, demographic, clinical and obstetric characteristics of women who received intrapartum care funded by public or private health care. Southeastern Brazil, February 2011 to July 2012.

\begin{tabular}{|c|c|c|c|c|c|}
\hline \multirow{2}{*}{ Characteristic } & \multicolumn{2}{|c|}{ Public } & \multicolumn{2}{|c|}{ Private } & \multirow{2}{*}{$\mathbf{p}^{\mathbf{b}}$} \\
\hline & $n$ & $\%$ & $\mathbf{n}$ & $\%$ & \\
\hline \multicolumn{6}{|l|}{ Maternal age (years) } \\
\hline $12-19$ & 1,487 & 19.7 & 128 & 5.7 & $<0.001$ \\
\hline $20-34$ & 5,396 & 71.3 & 1,716 & 76.0 & \\
\hline 35 or more & 683 & 9.0 & 415 & 18.3 & \\
\hline Total & $7,566^{a}$ & 100 & 2,259 & 100 & \\
\hline \multicolumn{6}{|l|}{ Skin colour } \\
\hline Indigenous & 25 & 0.3 & 5 & 0.2 & $<0.001$ \\
\hline Black & 835 & 11.0 & 95 & 4.2 & \\
\hline Brown & 4,139 & 54.8 & 835 & 36.9 & \\
\hline Oriental & 83 & 1,1 & 30 & 1,3 & \\
\hline White & 2,482 & 32,8 & 1,294 & 57.3 & \\
\hline Total & $7,564^{\mathrm{a}}$ & 100 & 2,259 & 100 & \\
\hline \multicolumn{6}{|l|}{ Education } \\
\hline Elementary school & 4,172 & 55.3 & 330 & 14.7 & $<0.001$ \\
\hline High school & 3,153 & 41.8 & 1,265 & 56.4 & \\
\hline College or more & 220 & 2.9 & 649 & 28.9 & \\
\hline Total & $7,545^{a}$ & 100 & $2,244^{a}$ & 100 & \\
\hline \multicolumn{6}{|l|}{ Marital status } \\
\hline With partner & 5,734 & 75.8 & 1,990 & 88.2 & $<0.001$ \\
\hline No partner & 1,832 & 24.2 & 267 & 11.8 & \\
\hline Total & $7,566^{\mathrm{a}}$ & 100 & $2,257^{\mathrm{a}}$ & 100 & \\
\hline \multicolumn{6}{|l|}{ Paid work } \\
\hline No & 4,790 & 63.3 & 674 & 29.8 & $<0.001$ \\
\hline Yes & 2,777 & 36.7 & 1,585 & 70.2 & \\
\hline Total & $7,567^{\mathrm{a}}$ & 100 & 2,259 & 100 & \\
\hline \multicolumn{6}{|l|}{ Economic class } \\
\hline$A$ or $B$ & 1,376 & 18.3 & 1,416 & 63.5 & $<0.001$ \\
\hline $\mathrm{C}$ & 4,780 & 63.5 & 770 & 34.5 & \\
\hline $\mathrm{D}$ or $\mathrm{E}$ & 1,372 & 18.2 & 45 & 2.0 & \\
\hline Total & $7,528^{\mathrm{a}}$ & 100 & $2,231^{\mathrm{a}}$ & 100 & \\
\hline \multicolumn{6}{|l|}{ Hospital location } \\
\hline Capital & 2,507 & 33.1 & 766 & 33.9 & 0.486 \\
\hline Regional & 5,062 & 66.9 & 1,493 & 66.1 & \\
\hline Total & 7,569 & 100 & 2,259 & 100 & \\
\hline \multicolumn{6}{|c|}{ Previous cesarian section } \\
\hline No & 2,603 & 34.4 & 350 & 15.5 & $<0.001$ \\
\hline Yes & 1,608 & 21.2 & 653 & 28.9 & \\
\hline Primiparae & 3,358 & 44.4 & 1,256 & 55.6 & \\
\hline Total & 7,569 & 100 & 2,259 & 100 & \\
\hline \multicolumn{6}{|c|}{ Antenatal complications } \\
\hline No & 4,161 & 55.0 & 1,378 & 61.0 & $<0.001$ \\
\hline Yes & 3,408 & 45.0 & 881 & 39.0 & \\
\hline Total & 7,569 & 100 & 2,259 & 100 & \\
\hline \multicolumn{6}{|l|}{ Labour complications } \\
\hline No & 2,312 & 30.5 & 675 & 29.9 & 0.016 \\
\hline Yes & 1,419 & 18.7 & 372 & 16.5 & \\
\hline No labour & 3,838 & 50.8 & 1,212 & 53.6 & \\
\hline Total & 7,569 & 100 & 2,259 & 100 & \\
\hline
\end{tabular}

aissing $<10 \%$.

${ }^{\mathrm{b}}$ Chi-squared test. 
as independent predictors of CS. Planned or emergency CS procedures could not be differentiated, as these data were not routinely documented in either sector in women's obstetric records. Because of this, the likelihood of a CS based on documented maternal or fetal complications was estimated using unadjusted and adjusted odds ratios (OR) with 95\% confidence intervals (CI). Analyses were conducted using SPSS version 22 (IBM Corp., Amork, United States).

The "Birth in Brazil" survey was approved by the Research Ethics Committee of Escola Nacional de Saúde Pública, Fundação Oswaldo Cruz (Process 92/10) and by the Research Ethics Committee of Faculdade de Saúde Pública, Universidade de São Paulo (Process 717 944/14). All participants of the survey provided written informed consent.

\section{RESULTS}

Mean maternal age was 26.3 years ( $\mathrm{SD}=6.4$, ranged from 13 to 49 years). Women's characteristics differed by how their maternity care was funded. Women whose care was publicly funded were more likely to be younger, of black or brown skin color, and from lower socioeconomic groups (C, D or E). They were more likely to have only attended elementary school, not to have a partner, and not to be in paid employment at pregnancy commencement. They were also more likely to have experienced pregnancy and labor complications in the index pregnancy and to not have had a previous CS $(\mathrm{p}<0.001)$ (Table 1$)$.

Table 2. Number and percentage of caesarean by characteristics of women and care funded from public or private health care. Southeastern Brazil, February 2011 to July 2012.

\begin{tabular}{|c|c|c|c|c|c|c|c|c|}
\hline \multirow{3}{*}{$\begin{array}{l}\text { Funding source } \\
\text { Variable }\end{array}$} & \multicolumn{4}{|c|}{ Public } & \multicolumn{4}{|c|}{ Private } \\
\hline & \multicolumn{2}{|c|}{ CS } & \multirow{2}{*}{$\begin{array}{c}\text { Total } \\
\mathbf{n}\end{array}$} & \multirow{2}{*}{$\mathbf{p}^{*}$} & \multicolumn{2}{|c|}{ CS } & \multirow{2}{*}{$\begin{array}{c}\text { Total } \\
\mathbf{n}\end{array}$} & \multirow{2}{*}{$\mathbf{p}^{*}$} \\
\hline & $\mathbf{n}$ & $\%$ & & & $\mathbf{n}$ & $\%$ & & \\
\hline Total & 3,288 & 43.4 & 7,569 & - & 1,916 & 84.8 & 2,259 & $<0.001$ \\
\hline \multicolumn{9}{|l|}{ Maternal age (years) } \\
\hline $12-19$ & 499 & 33.5 & 1,488 & $<0.001$ & 80 & 62.5 & 128 & $<0.001$ \\
\hline $20-34$ & 2,431 & 45.1 & 5,396 & & 1,465 & 85.4 & 1,716 & \\
\hline 35 or more & 358 & 52.4 & 683 & & 371 & 89.4 & 415 & \\
\hline \multicolumn{9}{|l|}{ Skin colour } \\
\hline Indigenous & 8 & 32.0 & 25 & $<0.001$ & 4 & 66.7 & 6 & $<0.001$ \\
\hline Black & 365 & 43.7 & 835 & & 79 & 84.0 & 94 & \\
\hline Brown & 1,686 & 40.7 & 4,139 & & 663 & 79.5 & 834 & \\
\hline Oriental & 34 & 41.0 & 83 & & 24 & 82.8 & 29 & \\
\hline White & 1,193 & 48.1 & 2,481 & & 1,146 & 88.5 & 1,295 & \\
\hline \multicolumn{9}{|l|}{ Education } \\
\hline Elementary school & 1,647 & 39.5 & 4,172 & $<0.001$ & 236 & 71.5 & 330 & $<0.001$ \\
\hline High school & 1,482 & 47.0 & 3,153 & & 1,081 & 85.5 & 1,265 & \\
\hline College or more & 149 & 67.7 & 220 & & 588 & 90.6 & 649 & \\
\hline \multicolumn{9}{|l|}{ Marital status } \\
\hline With partner & 2,584 & 45.1 & 5,734 & $<0.001$ & 1,688 & 84.9 & 1,989 & 0,799 \\
\hline No partner & 702 & 38.3 & 1,832 & & 225 & 84.3 & 267 & \\
\hline \multicolumn{9}{|l|}{ Paid work } \\
\hline No & 1,943 & 40.6 & 4,791 & $<0.001$ & 494 & 73.3 & 674 & $<0.001$ \\
\hline Yes & 1,344 & 48.4 & 2,777 & & 1,422 & 89.7 & 1,585 & \\
\hline \multicolumn{9}{|l|}{ Economic class } \\
\hline$A$ and $B$ & 682 & 49.6 & 1.376 & $<0.001$ & 1,240 & 87.6 & 1,416 & $<0.001$ \\
\hline $\mathrm{C}$ & 2,100 & 43.9 & 4,780 & & 619 & 80.5 & 769 & \\
\hline $\mathrm{D}$ and $\mathrm{E}$ & 489 & 35.7 & 1,371 & & 32 & 71.1 & 45 & \\
\hline \multicolumn{9}{|l|}{ Hospital location } \\
\hline Capital & 2,423 & 47.9 & 5,061 & $<0.001$ & 1,311 & 87.8 & 1,493 & $<0.001$ \\
\hline Countryside & 865 & 34.5 & 2,507 & & 605 & 79.0 & 766 & \\
\hline \multicolumn{9}{|c|}{ Previous cesarian section } \\
\hline No & 450 & 17.3 & 2,603 & $<0.001$ & 168 & 48.0 & 350 & $<0.001$ \\
\hline Yes & 1,311 & 81.5 & 1,608 & & 641 & 98.2 & 653 & \\
\hline Primiparae & 1,526 & 45.5 & 3,357 & & 1,107 & 88.1 & 1,256 & \\
\hline \multicolumn{9}{|c|}{ Antenatal complications } \\
\hline No & 1,548 & 37.2 & 4,161 & $<0.001$ & 1,143 & 82.9 & 1,378 & 0.002 \\
\hline Yes & 1,740 & 51.1 & 3,408 & & 773 & 87.7 & 881 & \\
\hline \multicolumn{9}{|l|}{ Labour complications } \\
\hline No & 747 & 32.3 & 2,312 & $<0.001$ & 561 & 83.2 & 674 & $<0.001$ \\
\hline Yes & 846 & 59.6 & 1,419 & & 346 & 93.0 & 372 & \\
\hline No labour & 1,695 & 44.2 & 3,838 & & 1,009 & 83.2 & 1,213 & \\
\hline
\end{tabular}

* Chi-squared test. 
Birth data were available for 9,828 women, $77.0 \%$ of whom had maternity care provided in the public health system $(\mathrm{n}=7,569)$ and $23.0 \%(\mathrm{n}=2,259)$ in the private sector. The overall CS rate was $53.0 \%$, with a significantly higher proportion of CS among women who had private health care: $84.8 \%(1,916 / 2,259)$ versus $43.4 \%(3,288 / 7,569), p<0.001$ (Table 2). Indications for planned or unplanned CS were missing for $47.9 \%$ of women $(4,863 / 10,156)$.

In contrast, women whose care was funded privately were more likely to be white and over 35 years of age, from higher socioeconomic groups (A or B) and to be primiparous. They were more likely to have attended college or have more education, to have a partner, to be in paid employment, and to have had a previous CS ( $\mathrm{p}<0.001)$ (Table 1$)$. The only variable that was not associated with CS in the private sector was marital status (Table 2).

In the adjusted multivariate analysis (Table 3), reduced likelihood of a CS birth in either sector was associated with younger maternal age and giving birth in a hospital located in a state capital city. Not having a partner was also associated with a lower likelihood of CS, but only

Table 3. Crude and adjusted odds ratio, $95 \%$ confidence intervals $(95 \% \mathrm{Cl})$ for variables associated with caesarean funded by public or private health care. Southeastern Brazil, February 2011 to July 2012.

\begin{tabular}{|c|c|c|c|c|c|c|c|c|}
\hline \multirow{2}{*}{$\begin{array}{l}\text { Funding source } \\
\text { Variable }\end{array}$} & \multicolumn{4}{|c|}{ Public } & \multicolumn{4}{|c|}{ Private } \\
\hline & OR crude & $95 \% \mathrm{Cl}$ & OR adjusted* & $95 \% \mathrm{Cl}$ & OR crude & $95 \% \mathrm{Cl}$ & OR adjusted* & $95 \% \mathrm{Cl}$ \\
\hline \multicolumn{9}{|l|}{ Maternal age (years) } \\
\hline $12-19$ & 0.61 & $0.55-0.69$ & 0.63 & $0.54-0.73$ & 0.28 & $0.19-0.42$ & 0.39 & $0.23-0.66$ \\
\hline $20-34$ & 1.00 & - & 1.00 & - & 1.00 & - & Ref. & - \\
\hline 35 or more & 1.34 & $1.14-1.57$ & 1.44 & $1.16-1.77$ & 1.45 & $1.03-2.04$ & 1.54 & $1.00-2.37$ \\
\hline \multicolumn{9}{|l|}{ Skin colour } \\
\hline Indigenous & 1.00 & - & 1.00 & - & 1.00 & - & 1.00 & - \\
\hline Black & 1.70 & $0.73-3.97$ & 2.53 & $0.94-6.80$ & 2.70 & $0.42-17.27$ & 4.34 & $0.52-34.84$ \\
\hline Brown & 1.50 & $0.65-3.48$ & 1.84 & $0.69-4.90$ & 2.03 & $0.34-12.03$ & 3.56 & $0.47-26.81$ \\
\hline Oriental & 1.51 & $0.59-3.89$ & 1.63 & $0.54-4.93$ & 2.38 & $0.32-17.66$ & 2.46 & $0.26-23.43$ \\
\hline White & 2.20 & $0.87-4.69$ & 2.37 & $0.89-6.31$ & 4.03 & $0.68-23.90$ & 4.76 & $0.63-35.71$ \\
\hline \multicolumn{9}{|l|}{ Education } \\
\hline Elementary school & 1.00 & - & 1.00 & - & 1.00 & - & 1.00 & - \\
\hline High school & 1.36 & $1.24-1.49$ & 0.96 & $0.849-1.092$ & 2.33 & $1.75-3.11$ & 0.94 & $0.63-1.40$ \\
\hline College or more & 3.23 & $2.41-4.31$ & 1.63 & $1.15-2.31$ & 3.82 & $2.68-5.46$ & 0.90 & $0.53-1.52$ \\
\hline \multicolumn{9}{|l|}{ Marital status } \\
\hline With partner & 1.00 & - & 1.00 & - & 1.00 & - & 1.00 & - \\
\hline No partner & 0.76 & $0.68-0.84$ & 0.81 & $0.71-0.92$ & 0.92 & $0.68-1.37$ & 0.98 & $0.64-1.50$ \\
\hline \multicolumn{9}{|l|}{ Paid work } \\
\hline No & 1.00 & - & 1.00 & - & 1.00 & - & 1.00 & - \\
\hline Yes & 1.37 & $1.25-1.51$ & 1.32 & $1.17-1.49$ & 3.18 & $2.51-4.03$ & 2.70 & $1.99-3.66$ \\
\hline \multicolumn{9}{|l|}{ Economic class } \\
\hline$A$ or $B$ & 1.78 & $1.52-2.06$ & 1.52 & $1.25-1.85$ & 2.80 & $1.44-5.45$ & 2.11 & $0.94-4.75$ \\
\hline C & 1.41 & $1.25-1.60$ & 1.36 & $1.17-1.58$ & 1.63 & $0.84-3.19$ & 2.12 & $0.94-4.75$ \\
\hline $\mathrm{D}$ or $\mathrm{E}$ & 1.00 & - & 1.00 & - & 1.00 & - & 1.00 & - \\
\hline \multicolumn{9}{|l|}{ Hospital location } \\
\hline Capital & 0.57 & $0.52-0.63$ & 0.49 & $0.44-0.56$ & 0.52 & $0.41-0.65$ & 0.49 & $0.37-0.65$ \\
\hline Regional & 1.00 & - & 1.00 & - & 1.00 & - & 1.00 & - \\
\hline \multicolumn{9}{|c|}{ Previous cesarian section } \\
\hline No & 1.00 & - & 1.00 & - & 1.00 & - & 1.00. & - \\
\hline Yes & 21.13 & $17.97-24.85$ & 22.46 & $18.94-26.64$ & 59.78 & $32.28-110.71$ & 58.22 & 30.78-110.13 \\
\hline Primiparae & 3.98 & $3.53-4.50$ & 4.74 & $4.11-5.47$ & 8.07 & $6.16-10.57$ & 8.64 & $6.20-12.02$ \\
\hline \multicolumn{9}{|c|}{ Antenatal complications } \\
\hline No & 1.00 & - & 1.00 & - & 1.00 & - & 1.00 & - \\
\hline Yes & 1.76 & $1.61-1.93$ & 1.60 & $1.43-1.78$ & 1.45 & $1.15-1.87$ & 1.39 & $1.03-1.87$ \\
\hline \multicolumn{9}{|l|}{ Labour complications } \\
\hline No & 0.60 & $0.54-0.67$ & 0.58 & $0.51-0.66$ & 1.00 & $0.77-1.28$ & 0.88 & $0.65-1.20$ \\
\hline Yes & 1.86 & $1.65-2.11$ & 1.99 & $1.72-2.30$ & 2.69 & $1.76-4.13$ & 3.56 & $2.16-5.93$ \\
\hline No labour & 1.00 & - & 1.00 & - & 1.00 & - & 1.00 & - \\
\hline
\end{tabular}

Values with statistical significance are shown in bold.

* Models adjusted for all variables presented in this table. 
in the public system. In contrast, having a CS in the publicly funded system was associated with older maternal age, more years in full-time education, being in paid employment, higher socioeconomic status, a previous CS, primiparity, and complications in the index pregnancy or labor. In the private sector, paid employment, a previous CS, primiparity, and complications in the index pregnancy or labor were associated with a CS.

Although some of the factors associated with a CS were common regardless of the source of health care funding, the magnitude of the effect differed. For example, women who had a previous CS were almost three times more likely to have another CS in the index pregnancy if their care was provided in the private sector (Table 3).

\section{DISCUSSION}

This is the first study to examine associations between maternal and obstetric characteristics, maternity funding, and impact on caesarean births in Southeast Brazil. There was an association between higher socioeconomic status, obstetric factors and CS births among women whose maternity care was publicly funded. Conversely, most maternal socioeconomic factors explored were not associated with a CS in the private sector, as most women in this sector were of higher socioeconomic status and had undergone extremely high rates of surgery.

Limitations include that indications associated with the medical need for CS birth could not be discriminated in the analyses, as these data were not routinely recorded. However, the high CS rate in our study, which was powered to represent the population of women giving birth in Southeastern Brazil, suggests that a significant number of operations was performed without medical indication in both sectors ${ }^{15}$. Study strengths include that variables incorporated information from maternal and neonatal records and postnatal interviews with women to verify and correct inconsistencies in routinely recorded data.

In the private health sector, few women may be offered the option of achieving a vaginal birth. This particular aspect of Brazilian maternity culture impairs examination of factors, such as failure to progress, fetal compromise or fetal malpresentation commonly associated with a higher CS rate $^{11,16}$. More than half of all women in both sectors had a pre-labor CS and $92 \%$ of these women had a late preterm baby ${ }^{4}$, which is likely to be detrimental to maternal and infant health and reflects a system of care that does not promote maternal choice with respect to normal birth.

The association between CS rate and private health care reflects findings from previous studies in Brazil ${ }^{17}$, United States ${ }^{18}$, and China ${ }^{19}$. A study that investigated CS rates in Peru showed an increase from 1991 to 1999 and from 1999 to 2008 of $24.5 \%$ in the privately funded sector and under $8 \%$ in the public sector ${ }^{20}$.

Factors including wide spread coverage of private healthcare, pregnancy, and birth care provided almost entirely by obstetricians (with labor and birth care provided by midwives or nurse-midwives ranging from $3 \%$ to $20 \%^{11}$ ) and convenience of scheduling surgery ${ }^{21,22}$ are possible explanations. Although payment for CS and vaginal births does not differ between private and public sectors, women who have spontaneous labor are likely to require clinical care over an undefined number of hours (unlike a scheduled CS). This condition has a strong influence on CS rates in Brazil ${ }^{11}$.

Higher socioeconomic status and university attendance did not influence CS rates in the private sector, as most women belonged to these groups. Despite the strong influence of these variables on CS section rates, the funding source was a decisive influence on the mode of birth among these women, independently of risk, a finding also reported in previous studies from Brazil ${ }^{10,11}$. Younger women were less likely to have a CS in the current study particularly in the public health system, presumably as they were less likely to have private healthcare and possibly more likely to have the support of a birth companion than older women in the study, with robust evidence that a birth companion reduces labor interventions ${ }^{9}$. As a first CS birth can negatively affect future maternity outcomes ${ }^{16}$, maternal age could have influenced decisions to progress to a CS. 
Findings support previous studies that CS rates increase with maternal age ${ }^{23}$. Factors commonly reported among older women (such as a previous CS) and increased risk of medical complications (such as hypertension or diabetes) offer potential justification for opting for a $\mathrm{CS}^{5}$. This is of concern for women, maternity care providers, and funders in many countries, with the current trend for women to delay their first pregnancy ${ }^{23}$.

Although years in full-time education and higher socioeconomic status were associated with increased likelihood of CS in the public sector, women's views suggest that a CS would not be a better first choice ${ }^{25}$. Women who did not have a partner were less likely to have a CS, but only if care was publicly funded, in which younger maternal age, being in a lower socioeconomic group, and having had a previous normal vaginal birth also influenced outcomes. Because these women were also unlikely to have paid for private maternity care, as described earlier, their chance of CS was reduced still further ${ }^{10}$.

The association with decreased CS in state capitals of the Southeastern Brazil regardless of funding source may reflect the ability of maternity care providers in these settings to implement evidence-based guidance to support normal birth ${ }^{26}$, although the proportion of CS births was smaller following bivariate analysis. Reasons are likely to be complex, but some factors may have inverted the trend of the likelihood for a CS birth, such as women being more likely to have information to inform decision making, and evidence that regional hospitals are facing cuts to resources including qualified clinicians and are less likely to promote the implementation of evidence-based practice ${ }^{27}$.

Nevertheless, despite evidence that vaginal birth after a caesarean section is a safe alternative for women who had a previous $\mathrm{CS}^{28}$, it did not appear to have been routinely offered to women in either sector. Although primiparous women had an increased chance of a CS regardless of maternity care funding, it was more likely to be offered to women who had private health care, despite recommendations to avoid a first $\mathrm{CS}^{16}$. Primiparous women have longer labors and robust data has shown ${ }^{29}$ that progress of labor is slower than originally proposed by Friedman, although the latter's work is still likely to influence decisions about progression to a CS.

Complications during pregnancy also increased the chance of a CS regardless of how care was funded. Women whose care was provided by the public system may have had more serious problems requiring intervention ${ }^{30}$. Even after adjusting for other potential confounders, there was no association with pregnancy complications in women who did not go into labor in the private care sector, possibly as data on too few women were available ${ }^{31}$.

Rates of CS were high in the Southeast region of Brazil, especially among women who had private health care, with socioeconomic status being an important predictor of CS. The regulation of obstetric practice in privately funded care is urgently needed, given that this is a sector that provides maternity care for a large proportion of women in this region. Qualitative studies are also needed to better understand reasons for CS among women of higher socioeconomic status who receive publicly funded care. Measures to support normal birth and better information on birth choices for women and their families are essential to encourage informed choice and decision making on benefits and consequences of the mode of birth for all women giving birth in Brazil.

\section{REFERENCES}

1. World Health Organization, Department of Reproductive Health and Research. WHO statement on caesareans rates. Geneva: WHO; 2015 [cited 2017 Jul 13]. Available from: http://apps.who.int/iris/bitstream/10665/161442/1/WHO_RHR_15.02_eng.pdf

2. Gibbons L, Belizan JM, Lauer JA, Betran AP, Merialdi M, Althabe F. Inequities in the use of cesarean section deliveries in the world. Am J Obstet Gynecol. 2012;206(4):331.e1-19. https://doi.org/10.1016/j.ajog.2012.02.026

3. Raifman S, Cunha AJ, Castro MC. Factors associated with high rates of caesarean section in Brazil between 1991 and 2006. Acta Paediatr. 2014;103(7):e295-9. https://doi.org/10.1111/apa.12620 
4. Leal MC, Pereira APE, Domingues RMSM, Theme Filha MM, Dias MAB, Nakamura-Pereira M, et al. Obstetric interventions during labor and childbirth in Brazilian low-risk women.Cad Saude Publica. 2014;30 Suppl 1:S17-32. https://doi.org/10.1590/0102-311X00151513

5. Domingues RMSM, Dias MAB, Nakamura-Pereira M, Torres JA, d'Orsi E, Pereira APE, et al. Process of decision-making regarding the mode of birth in Brazil: from the initial preference of women to the final mode of birth. Cad Saude Publica. 2014;30 Suppl 1:S101-16. https://doi.org/10.1590/0102-311X00105113

6. Declercq E, Menacker F, MacDorman M. Rise in "no indicated risk" primary caesareans in the United States, 1991-2001: cross sectional analysis. BMJ. 2005;330(7482):71-2. https://doi.org/10.1136/bmj.38279.705336.0B

7. Barber EL, Lundsberg LS, Belanger K, Pettker CM, Funai EF, Illuzzi JL. Indications contributing to the increasing cesarean delivery rate. Obstet Gynecol. 2011;118(1):29-38. https://doi.org/10.1097/AOG.0b013e31821e5f65

8. Bragg F, Cromwell DA, Edozien LC, Gurol-Urganci I, Mahmood TA, Templeton A, et al. Variation in rates of caesarean section among English NHS trusts after accounting for maternal and clinical risk: cross sectional study. BMJ. 2010;341:c5065. https://doi.org/10.1136/bmj.c5065

9. Hodnett ED, Gates S, Hofmeyr GJ, Sakala C. Continuous support for women during childbirth. Cochrane Database Syst Rev. 2013;7:CD003766. https://doi.org/10.1002/14651858.CD003766.pub5

10. Hopkins K, Lima Amaral EF, Mourao AN. The impact of payment source and hospital type on rising cesarean section rates in Brazil, 1998 to 2008. Birth. 2014;41(2):169-77. https://doi.org/doi.org/10.1111/birt.12106

11. Barros AJD, Santos IS, Matijasevich A, Domingues MR, Silveira M, Barros FC, et al. Patterns of deliveries in a Brazilian birth cohort: almost universal cesarean sections for the better-off. Rev Saude Publica. 2011;45(4):635-43. https://doi.org/10.1590/S0034-89102011005000039

12. Leal MC, Silva AAM, Dias MAB, Gama SGN, Rattner D, Moreira ME, et al. Birth in Brazil: national survey intolabour and birth. Reprod Health. 2012;9:15. https://doi.org/10.1186/1742-4755-9-15

13. Vasconcellos MTL, Silva PLN, Pereira APE, Schilithz AOC, Souza Junior PRB, Szwarcwald CL. Sampling design for the Birth in Brazil: National Survey into Labor and Birth. Cad Saude Publica. 2014;30 Suppl 1:S49-58. https://doi.org/10.1590/0102-311X00176013

14. Viellas EF, Domingues RMSM, Dias MAB, Gama SGN, Theme Filha MM, Costa JV, et al. Prenatal care in Brazil. Cad Saude Publica. 2014;30 Suppl 1:S85-100. https://doi.org/10.1590/0102-311X00126013

15. Souza JP, Gulmezoglu A, Lumbiganon P, Laopaiboon M, Carroli G, Fawole B, et al. Caesarean section without medical indications is associated with an increased risk of adverse short-term maternal outcomes: the 2004-2008 WHO Global Survey on Maternal and Perinatal Health. BMC Med. 2010;8:71. https://doi.org/10.1186/1741-7015-8-71

16. American College of Obstetricians and Gynecologists; Society for Maternal-Fetal Medicine. Obstetric care consensus $\mathrm{n}^{\circ} 1$ : safe prevention of the primary cesarean delivery. Obstet Gynecol. 2014;123(3):693-711. https://doi.org/10.1097/01.AOG.0000444441.04111.1d

17. Leal MC, Esteves-Pereira AP, Nakamura-Pereira M, Torres JA, Domimgues RM, Dias MA, et al. Provider-initiated late preterm births in Brazil: differences between public and private health services. PLoS One. 2016;11(5):e0155511. https://doi.org/10.1371/journal.pone.0155511

18. Declercq ER, Sakala C, Corry MP, Applebaum S, Herrlich A. Listening to mothers ${ }^{\text {SM III: }}$ pregnancy and birth. New York: Childbirth Connection; 2013 [cited 2017 Jul 19]. Available from: http://transform.childbirthconnection.org/wp-content/uploads/2013/06/LTM-III_ Pregnancy-and-Birth.pdf

19. Feng $X L, X \cup L, G u o Y$, Ronsmans $C$. Factors influencing rising caesarean section rates in China between 1988 and 2008. Geneva, Switzerland: Bull Worl Health Organ. 2012;90:30-9A. htttps://doi.org/10.2471/BLT.11.090399

20. Arrieta A. Health reform and cesarean sections in the private sector: the experience of Peru. Health Policy. 2011;99(2):124-30. https://10.1016/j.healthpol.2010.07.016

21. Hopkins K. Are Brazilian women really choosing to deliver by cesarean? Soc Sci Med. 2000;51(5):725-40. https://doi.org/10.1016/S0277-9536(99)00480-3

22. Potter JE, Berquó E, Perpétuo IH, Leal OF, Hopkins K, Souza MR, et al. Unwanted caesarean sections among public and private patients in Brazil: prospective study. BMJ. 2001;323(7322):1155-8. https://doi.org/10.1136/bmj.323.7322.1155 
23. Baghurst P, Robson S, Antoniou G, Scheil W, Bryce R. The association between increasing maternal age at first birth and decreased rates of spontaneous vaginal birth in South Australia from 1991 to 2009. Aust N Z J Obstet Gynaecol. 2014;54(3):237-43. https://doi.orhg/10.1111/ajo.12182

24. Smith GCS, Cordeaux Y, White IR, Pasupathy D, Missfelder-Lobos H, Pell JP, et al. The effect of delaying childbirth on primary cesarean section rates. PLoS Med. 2008;5(7):e144. https://doi.org/10.1371/journal.pmed.0050144

25. Bittencourt SDA, Reis LGC, Ramos MM, Rattner D, Rodrigues PL, Neves DCO, et al. Structure in Brazilian maternity hospitals: key characteristics for quality of obstetric and neonatal care. Cad Saude Publica. 2014;30 Suppl 1:S208-19. http://dx.doi.org/10.1590/0102-311X00176913

26. Diniz CSG. [Humanization of childbirth care in Brazil: the numerous meanings of a movement]. Cienc Saude Coletiva. 2005;10(3):627-37. Portuguese. https://doi.org/10.1590/S1413-81232005000300019

27. Dodd JM, Crowther CA, Huertas E, Guise JM, Horey D. Planned elective repeat caesarean section versus planned vaginal birth for women with a previous caesarean birth. Cochrane Database Syst Rev. 2013;(12):CD004224. https://doi.org/10.1002/14651858.CD004224.pub3

28. Zhang J, Landy HJ, Branch DW, Burkman R, Haberman S, Gregory KD, et al. Contemporary patterns of spontaneous labor with normal neonatal outcomes. Obstet Gynecol. 2010;116(6):1281-7. https://doi.org/10.1097/AOG.0b013e3181fdef6e

29. Räisänen S, Gissler M, Kramer MR, Heinonen S. Influence of delivery characteristics and socioeconomic status on giving birth by caesarean section: a cross sectional study during 2000-2010 in Finland. BMC Pregnancy Childbirth. 2014;14:120. https://doi.org/10.1186/1471-2393-14-120

30. Victora CG, Aquino EM, Leal M, Monteiro CA, Barros FC, Szwarcwald CL. Maternal and child health in Brazil: progress and challenges. Lancet. 2011;377(9780):1863-76. https://doi.org/10.1016/S0140-6736(11)60138-4

Funding: Master's Degree benefit by CAPES for BDA (Process 1206013).

Authors' Contribution: Study design and planning: BDA, FMBS. Data collection, analysis, and interpretation: BDA, FMBS, MRDOL, CSGD, DB. Elaboration or revision of the manuscript: BDA, FMBS, MRDOL, CSGD, DB. Final version approval: BDA, FMBS, MRDOL, CSGD, DB. Public responsibility for the content of the article: BDA, FMBS, MRDOL, CSGD, DB.

Conflict of Interest: The authors declare no conflict of interest. 